Chapter 6

\title{
Computer Modelling of Radial-Direct Extrusion of Porous Powder Billets
}

\author{
Lyudmila Ryabicheva and Dmytro Usatyuk \\ Additional information is available at the end of the chapter \\ http://dx.doi.org/10.5772/57142
}

\section{Introduction}

Improving the competitiveness of engineering products related to enhancement of extrusion technologies using computer modelling of the material behaviour that allows production of high-quality products (Aliev et al., 2001; Favrot et al., 1997, Ryabicheva, 2012).

It is well known that a wide range of complex-shaped parts with flanges and spherical cavities are applied in machine-building and operating at variable loadings and high wear conditions. This is why the mentioned parts are produced of compact materials by various types of extrusion. The extrusion techniques are less used for production parts from powder materials due to presence of residual porosity and density variation. The extrusion technologies for parts with spherical cavities producing in the automotive industry have studied insufficiently. Production of parts may be carried out using various deformation schemes by selection the optimal initial shape and porosity of billets, as well as the deformation temperature. The most common process flowsheet for parts from powder materials is the scheme involving pressing of billet (compact), sintering and subsequent final stamping to obtain the necessary accuracy and density (Ryabicheva et al., 2011).

Finite element simulation is the most effective way for determination of optimal process variables of forming operations. However, simulation of extrusion of porous billets from powder materials with taking into account dependences of mechanical properties from porosity, thermal and strain rate deforming conditions does not allow to estimate the convergence of finite element method (Awrejcewicz et al., 2004; Awrejcewicz \& Pyryev, 2009). Mathematical formulation of the nonlinear coupled thermal plasticity problem makes necessary implementation of advanced solution methods for systems of linear algebraic equations (Awrejcewicz et al., 2007). 
This work aims on improvement a quality of automotive parts based on a theoretical analysis of the stress-strain state, temperature fields and density distribution during radial-direct extrusion of porous powder billets.

\section{The mathematical model of radial direct extrusion of porous powder billets}

In this chapter mathematical modelling has been conducted on the basis of plasticity theory of porous bodies and focused on sequential solving the following problems:

1. construction a system of differential equations of the nonlinear coupled thermal plasticity problem for three-dimensional model of billet-stamp system on the basis of the laws of plasticity theory of porous bodies with taking into account density distribution and other singularities of deformable porous body (Awrejcewicz et al., 2007; Ryabicheva \& Orlova, 2012; Segal et al., 1981);

2. application of a finite element method for solving of nonlinear coupled thermal plasticity problem (Awrejcewicz et al., 2007, Lienhard IV \& Lienhard V, 2003);

3. proving the stability of the finite element solution for the examined class of problems (Lienhard IV \& Lienhard V, 2003; Awrejcewicz et al., 2007; Awrejcewicz \& Pyryev, 2009);

4. formulation of the method and solving of physically nonlinear coupled thermal plasticity problem for a three-dimensional billet-stamp model of radial-direct extrusion of porous powder billets and examine the influence of temperature and deformation fields' coupling on simulation results (Awrejcewicz et al., 2007; Awrejcewicz\& Pyryev, 2009; Ryabicheva, 2012);

5. verification of the results of finite element simulation by experimental investigation of radial-direct extrusion of porous powder billets (Ryabicheva et al., 2012).

The plastic potential is considered as a function of stress tensor components corresponding to smooth, convex, closed surface into the stress space (Shtern et al., 1982; Ryabicheva \& Orlova, 2012). This potential may be presented in the following way (Shtern, 1981; Segal et al., 1981):

$$
F=\frac{\tau^{2}}{\varphi}+(1+m)^{2} \frac{\left(p+\frac{m}{m+1} \bar{\rho} \sigma_{s} \sqrt{\psi}\right)^{2}}{\psi}-\bar{\rho} \sigma_{s^{\prime}}
$$

where $p=\frac{1}{3} \sigma_{i j} \delta_{i j}$ - is the medium pressure;

$\tau=\sqrt{\left(\sigma_{i j}-p \delta_{i j}\right)\left(\sigma_{i j}-p \delta_{i j}\right)}$ - is the intensity of shear stress;

$\varphi=(1-\theta)^{2}, \psi=\frac{2}{3} \frac{(1-\theta)^{2}}{\theta}$ - are porosity functions; 
$\theta$ - is the porosity;

$\bar{\rho}=1-\theta$ - is the relative density;

$\mathrm{m}$ - is the parameter characterizing the degree of imperfection of the contacts in the powder billet and defining different resistance of a porous body during its testing in tension and compression. The rate of volume change resulting from the plastic deformation is presented by the expression (Shtern et al., 1982; Segal et al., 1981):

$$
e \sim \frac{2(1+m)^{2}}{\psi} p+\frac{2 m(1+m) \sigma_{0}}{\sqrt{\psi}}
$$

where $\sigma_{0}$ - is the flow stress of hard phase, which is a function of accumulated deformation $\omega$ and is determined by a hardening curve of powder material at uniaxial tension.

A flow stress of hard phase may be expressed as the function $\sigma=\sigma_{0}+K \omega^{0.5}$, where $\mathrm{K}$ - is the hardening coefficient. The rate of accumulating deformation in hard phase of porous body was determined on the basis of postulate of uniqueness of the dissipation function formulated by Skorokhod V.V. (Skorokhod, 1973):

$$
\omega=\sqrt{1-\theta}\left(\frac{m}{1+m} \sqrt{\psi} e+\frac{\sqrt{(1+m)^{2} \gamma^{2}+e^{2} \psi}}{1+m}\right),
$$

where $\gamma$ - is the shape changing rate.

The value of accumulated deformation $\omega$ is renewed by solving of differential equation (Skorokhod, 1973; Shtern et al., 1982; Segal et al., 1994):

$$
\frac{d \omega}{d t}=W
$$

where $\mathrm{W}$ - is the equivalent strain rate:

$$
W=\frac{1}{\sqrt{1-\Theta}} \sqrt{\psi e^{2}+\varphi \gamma^{2}}
$$

The finite element method presented as a series of procedures has used for determination of distributions of stress and strain intensity, as well as density in the volume of porous billet. The first procedure is triangulation of plastically deformed body or transition from a continuum billet to its finite element counterpart. Such simulation requires implementation of extremal requirement for the functional (Shtern et al., 1982, Segal et al., 1981): 


$$
J\left(\mathrm{v}_{i}(x)\right)=\int_{\Omega} D\left(e_{i j}\left(\mathrm{~V}_{\mathrm{i}}\right)\right) d \Omega+\int_{\partial \Omega_{p}} p_{i} \mathrm{v}_{i} d(\partial \Omega)
$$

where $D\left(e_{i j}\left(V_{i}\right)\right)$ - is the dissipative function;

$p_{i}$ - is the stress vector on the surface of the processed billet;

$v_{i}$ - is the velocity vector on the surface of the processed billet.

The first integral in (6) is the total rate of energy dissipation, the second integral - is the power of the external stresses. For a porous body, which deforms plastically, the dissipation function $D\left(e_{i j}\left(V_{i}\right)\right)$ may be presented by the following expression (Shtern et al., 1982):

$$
D\left(e_{i j}\left(V_{i}\right)\right)=\frac{\sqrt{\gamma^{2} \phi+e^{2} \psi}}{\sqrt{1-\theta}} \tau_{s}+\frac{p_{0} e}{\sqrt{1-\theta}}
$$

where $V_{i}=v(x), e_{i j}=\frac{1}{2}\left(\frac{\partial v_{i}}{\partial x_{j}}+\frac{\partial v_{j}}{\partial x_{i}}\right), p_{0}=-\sqrt{\frac{2}{3}} \tau_{s} \sqrt{\psi} \frac{m}{1+m}, \tau_{s}$ - is the shear yield stress.

The stress-strain state of porous powder billet and density distribution at radial direct extrusion may be calculated using dependences (1) - (7) and specific mathematical approaches with implementation of a Hilbert space (Awrejcewicz et al., 2007) and advanced solution method for a system of linear algebraic equations obtained by finite element discretization of a volume of porous powder billet (Awrejcewicz et al., 2007, Awrejcewicz \& Pyryev, 2009, Ryabicheva et al., 2012).

The technology of radial direct extrusion of forged pieces from water atomized steel powder Ancorstee ${ }^{\circledR} 150 \mathrm{HP}$ with a spherical cavity and small flange with the ratio $D_{\text {flange }} / D_{\text {out }}=1.1$ has been considered.

Temperature changes by sections of billet were determined using a heat conduction law. The analysis of interaction of contact surfaces has been conducted during each loading step, so, for elements inside of billet and in contact with tool surfaces heat conduction is determined only. The Fourier heat conduction differential equation was implemented for calculation of temperature field (Lienhard IV \& Lienhard V, 2003):

$$
k_{T}\left(\frac{\partial^{2} T}{\partial x^{2}}+\frac{\partial^{2} T}{\partial y^{2}}+\frac{\partial^{2} T}{\partial z^{2}}\right) d V=C \rho \frac{\partial T}{\partial \tau} d V
$$

where

$\mathrm{k}_{\mathrm{T}}$ - is the summary heat conduction coefficient;

$\mathrm{C}$ - is the specific heat capacity; 
Q - is the density of material;

$\mathrm{T}$ - is the temperature, $\mathrm{K}$;

$\tau$ - is the loading time step.

The minimum of heat conduction functional is related to each loading step (Segal et al., 1981; Lienhard IV \& Lienhard V, 2003):

$$
Q=\iiint_{V} k_{T}\left(\frac{\partial^{2} T}{\partial x^{2}}+\frac{\partial^{2} T}{\partial y^{2}}+\frac{\partial^{2} T}{\partial z^{2}}\right) d V
$$

The outward heat transfer between medium and surface of the billet is carrying out by convective heat transfer. The boundary conditions of the third kind have implemented on the surface of the billet (Lienhard IV \& Lienhard V, 2003; Ryabicheva et al., 2012):

$$
\alpha^{\prime}\left(T_{0}-T_{n p}\right)=-\lambda^{\prime}\left(\frac{\partial T}{\partial \tau}\right)
$$

where $\alpha^{\prime}$ - is the heat-transfer coefficient;

$\lambda^{\prime}$ - is the heat conduction coefficient;

$\frac{\partial T}{\partial \tau}{ }^{\prime}$ - is the temperature gradient.

The predictor-corrector method and Arbitrary Lagrangian Eulerian (ALE) formulation were implemented for more effective solving of nonlinear coupled thermal plasticity problem and prevention of gradual distortion of mesh due to severe plastic deformations during radialdirect extrusion. The transfinite mapping method is used to create an initial mesh and remeshing (Wisselink, 2000; Stoker, 1999).

\section{Initial data for modelling}

Two variants of radial direct extrusion, which are different by a shape of initial billet, have been considered. The first variant of billet is the bushing with a hole and the second is the bushing with a hole and a spherical cavity in the upper butt end. The input data for simulation: the strain rate is $0.5 \mathrm{~m} / \mathrm{s}$, deformation temperature interval is $1100-900{ }^{\circ} \mathrm{C}$, friction coefficient 0.2 , initial porosity of powder billet is $15 \%$. The dimensions of billet for extrusion by the first variant: the outer diameter $D_{\text {init }}$ is $27 \mathrm{~mm}$, hole diameter $9 \mathrm{~mm}$, height $31 \mathrm{~mm}$, diameter of forged piece $28 \mathrm{~mm}$, flange diameter $30.8 \mathrm{~mm}$, height $26 \mathrm{~mm}$, hole diameter $8.5 \mathrm{~mm}$, die preheating temperature $200{ }^{\circ} \mathrm{C}$. Material of stamp is die steel 5HNV GOST $5950-2000$. The finite element model of the billet-stamp system at the beginning and the end of the extrusion is presented in Fig. 1. 
Analysis of the stress-strain state and temperature field were performed in sections of billet, as shown in Fig. 2. The effective method to reduce a non-uniformity of the stress-strain state during extrusion is formation of relieving cone-shaped cavity in the initial billet (Fig. 4). According to the recommendations (Ryabicheva et al., 2011), relieving cavity for reducing of significant non-uniformity of stress-strain state in the upper end of the billet has made. The simulation scheme is presented in Fig. 3. It was assumed for simulation that the cavity depth is equal to the radius of the sphere, the cone angle was equal to $15^{\circ}, 30^{\circ}$ and $40^{\circ}$.

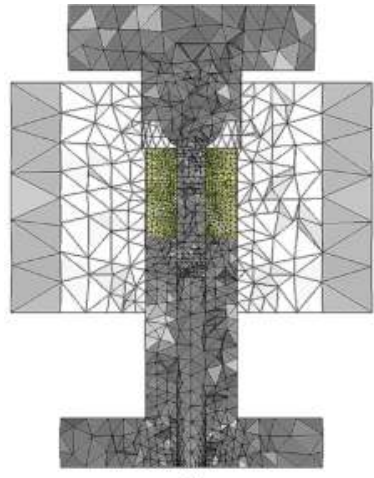

(a)

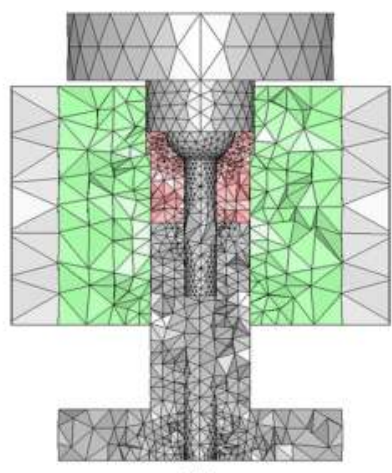

(b)

Figure 1. The model of the billet-stamp system: (a) - is the starting position, (b) - is the extrusion stage.

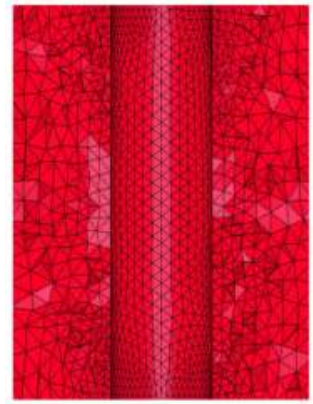

(a)

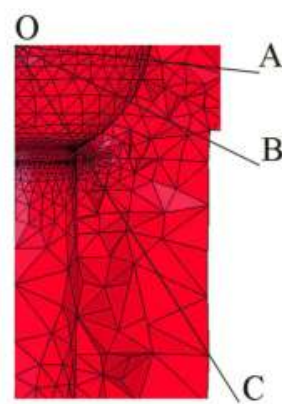

(b)

Figure 2. The model of initial billet - (a), section of forged piece for analysis of the stress-strain state - (b). 


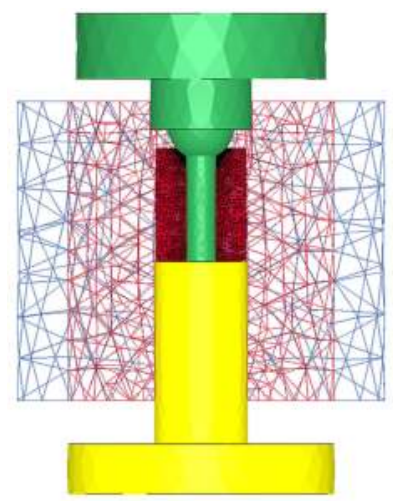

(a)

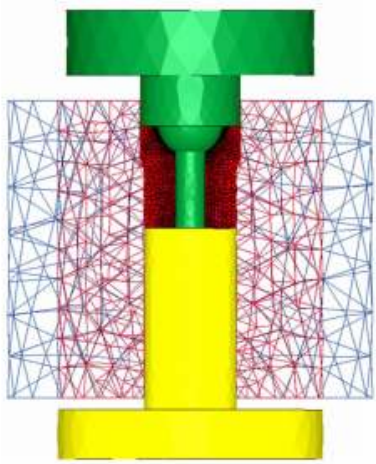

(b)

Figure 3. The model of the billet-stamp system for extrusion of billet with a relieving cavity: (a) - is the starting position, (b) - is the extrusion stage.

Drawings of initial porous powder billets are presented in Fig. 4.

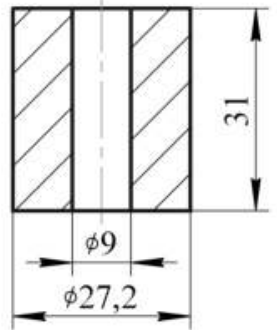

(a)

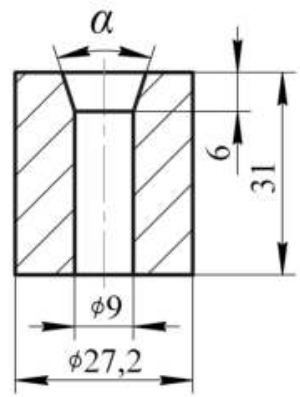

(b)

Figure 4. Drawings of initial porous powder billets: (a) - is the billet without relieving cavity; (b) - is the billet with relieving cavity.

\section{Computer simulation of radial-direct extrusion of forged piece with a spherical cavity and flange from cylindrical billet with axial hole}

Finite element simulation of extrusion of forged piece from cylindrical billet with a hole has shown clearly that maximum intensities of stress and deformation observed in the surface layers of the spherical cavity by sections of forged piece $\mathrm{OA}, \mathrm{OB}$ and $\mathrm{OC}$. These values were decreased gradually while increasing the distance from the surface of the forged piece (Fig. 5). The maximum values of the studied variables and dramatic non-uniformity of stress-strain 
state have been observed in the section OC, where the highest probability of defects formation established. The intensity of stress reduced to 5.28 times while growing the distance from the surface of the forged piece, the intensity of deformation decreased to 1.6 times. At a distance of $1.8-2.0 \mathrm{~mm}$ from the surface of the cavity there is a maximum of values due to overcooling of the metal in the area of transition of spherical cavity to the hole.

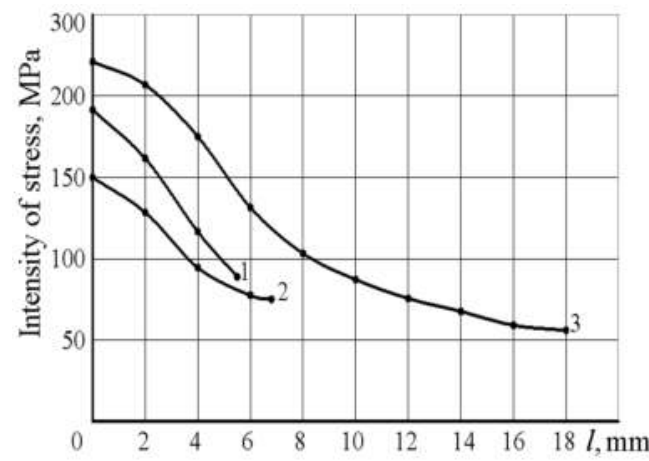

(a)

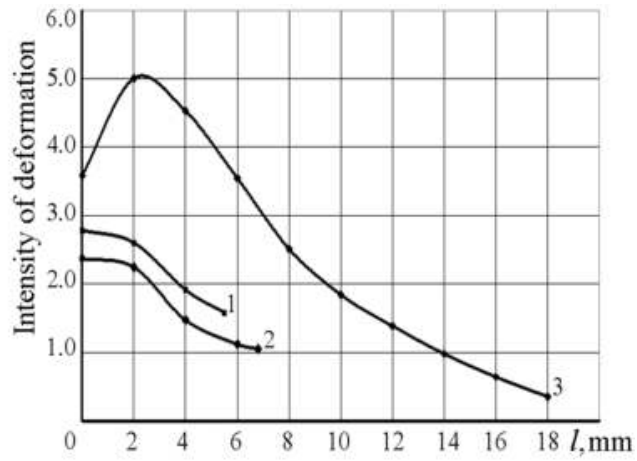

(b)

Figure 5. Distribution of the intensity of stress and intensity of deformation during extrusion of billet with a cylindrical hole in the sections: 1 - OA; 2 - OB; 3 - OC.

Non-uniformity of stress-strain state is a significant cause of non-uniformity of the temperature field (Fig. 6). The temperature rises up to $1200^{\circ} \mathrm{C}$ due to the thermal effect of plastic deformation while increasing the distance from the surface of the billet. The overcooled layer is formed at the points of contact with the forging tool due to heat transfer by conduction and convection.
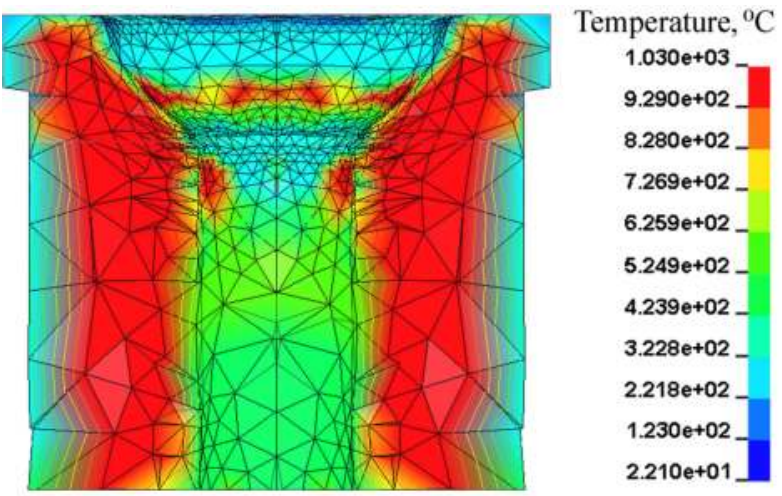

Figure 6. The temperature field of billet at extrusion of cylindrical powder billets with a hole. 
Non-uniformity of temperature field and stress-strain state of forged piece creates conditions for the formation of the fold at a distance of $2-3 \mathrm{~mm}$ from the edge of the hole, which is gradually transformed into the flow-through flaw and then leads to loss of plastic equilibrium and cracking of products. The stages of flow-through flaw defect evolution (Fig. 7, a) to the fold (Fig. 7, b, c) and crack (Fig. 7, d) have been observed. The retraction of the surface layer inside of forged piece around the flaw transforms it to the fold. Later, under pressure from a punch, the cavity of fold collapses, edges sharpening and becoming stress concentrators with following initiation and propagation of crack and formation of failure.

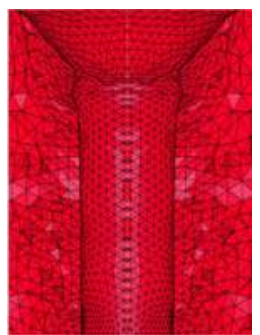

(a)

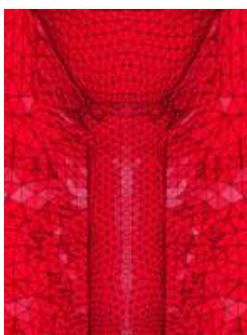

(b)

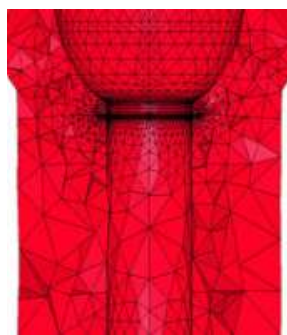

(c)

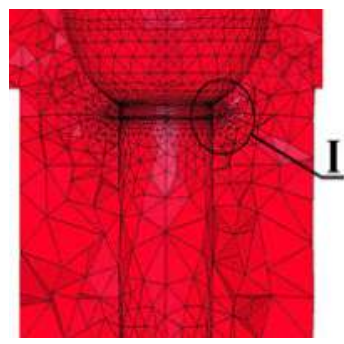

(d)

Figure 7. Evolution of flow-through flaw to a fold at extrusion of powder billets with cylindrical hole.

The stress state near the defect is significantly non-uniform (Fig. 8) and in the layers of metal adjacent to the surface of the fold, the stress intensity was about 160 - $240 \mathrm{MPa}$ and the stress intensity corresponds to the lower edge of the spherical cavity surface within $180-250 \mathrm{MPa}$.

Estimation of stress concentration, considering the influence of temperature and strain rate conditions on properties of deformable material has provided using technical stress concentration factor $\mathrm{a}_{\sigma}$ with taking into account the structure and plastic properties of powder material (Skorokhod, 1985; Ryabicheva, 2012):

$$
a_{\sigma}=\frac{\sigma_{i}^{\max }}{\sigma_{i}},
$$

where $\sigma_{i}^{\max }$ - is the highest intensity of stress near the defect;

$\sigma_{i}$ - is the intensity of stress under the given deforming conditions.

Stress concentration factor on the surface of forged piece $a_{\sigma}=2.5$ - 3.0. After closure of the fold stress concentrator formed at its end, leading to increase in stress concentration factor $\mathrm{a}_{\sigma}$ up to $4.0-6.0$, resulting formation of cracks into the forged piece. This promotes the evolution of folds in a failure, and also causes deterioration of the spherical surface in the region of its transition into the inner hole. This cracking is accompanied by stress relaxation, which leads to reduction of stress down to $70 \mathrm{MPa}$ after crack propagation. 


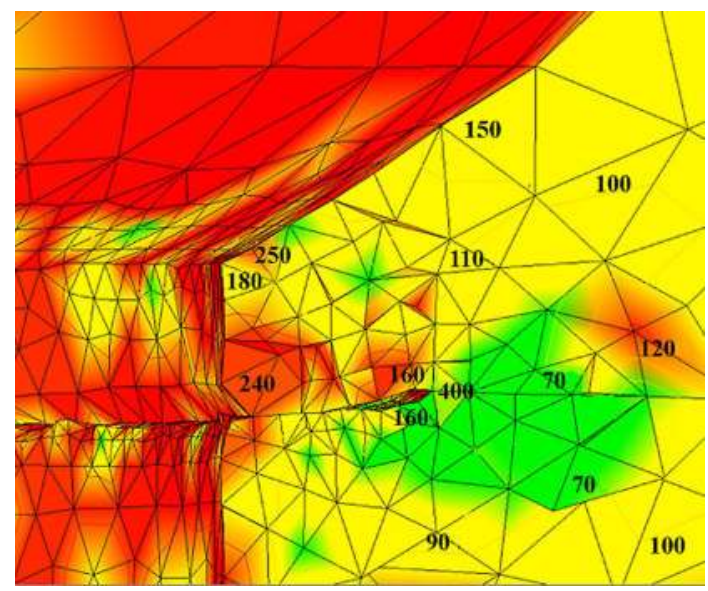

Figure 8. The stress state during the evolution of fold to crack.

The non-uniformity coefficients of stress $\sigma_{\text {inh }}$ and deformations $\mathrm{e}_{\mathrm{inh}}$ were implemented for estimation the non-uniformity of stress-strain state:

$$
\sigma_{i n h}=\frac{\sum_{j=1}^{N} \sqrt{\left(\sigma_{i}^{a v e}-\sigma_{i}^{j}\right)^{2}}}{\sigma_{i}^{a v e} N}, \quad e_{i n h}=\frac{\sum_{j=1}^{N} \sqrt{\left(e_{i}^{a v e}-e_{i}^{j}\right)^{2}}}{e_{i}^{a v e} N},
$$

where $\sigma_{i}^{\text {ave }}$ - is the average stress intensity in the volume of billet;

$\dot{\varepsilon}_{i}^{a v e}$ - is the average intensity of deformation in the volume of billet;

$\sigma_{i}^{j}$ - is the stress intensity into a finite element $\mathrm{j}$;

$\dot{\varepsilon}_{i}^{j}$ - is the intensity of deformation into a finite element $\mathrm{j}$;

$\mathrm{N}$ - is the number of finite elements inside the model.

In case of uniform deformation the values of $\sigma_{\mathrm{inh}}$ and $\mathrm{e}_{\mathrm{inh}}$ are asymptotically approaching zero.

The results of analysis of non-uniformity of stress-strain state by sections of forged piece confirms that the highest non-uniformity of stress-strain state has been observed in section OC, which corresponds to retraction of surface layers of the metal during formation of flowthrough flaw (Table 1).

Thus, conditions that are leading to formation of defects have established by numerical simulation of extrusion of the porous powder billet with a hole. 


\begin{tabular}{ccc}
\hline Section of billet & $\boldsymbol{\sigma}_{\text {inh }}$ & $\mathbf{e}_{\text {inh }}$ \\
\hline OA & 0.29 & 0.31 \\
\hline OB & 0.33 & 0.36 \\
\hline OC & 0.41 & 0.56 \\
\hline
\end{tabular}

Table 1. Non-uniformity of stress-strain state by sections of forged piece

\section{Computer simulation of radial-direct extrusion of forged piece with the spherical cavity and flange from cylindrical compact with axial hole and relieving cavity}

The effect of the generatrix inclination angle $\alpha$, radius of sphere $\mathrm{R}$ and size of cone-shaped relieving cavity on the non-uniformity of stress-strain state and temperature field has been investigated. The angle $\alpha$ was equal to $15^{\circ}, 30^{\circ}, 40^{\circ}$ and sphere's radius have changed from 6 to $16 \mathrm{~mm}$.

As a result of implementation the relieving cavity with $\alpha=15^{\circ}$, the non-uniformity of stressstrain state decreased, in compare with extrusion of billet without the cavity, but was not completely eliminated (Fig. 9). The maximum stress intensities in the surface layers of the spherical cavity of forged piece for all three sections have found (Fig. 9, a). The intensity of stress decreases at increasing of the distance from the cavity surface, especially in the most dangerous section OC down to $52 \mathrm{MPa}$. Intensity of deformation maximized at the distance of 1.9 - $2.4 \mathrm{~mm}$ from the surface, indicating the risk of flow-through flaw formation, and then also decreased (Fig. 9, b).

In this case, the intensity of stress and deformation values during extrusion of billet with generatrix inclination angle of relieving cavity $15^{\circ}$ are lower than without it.

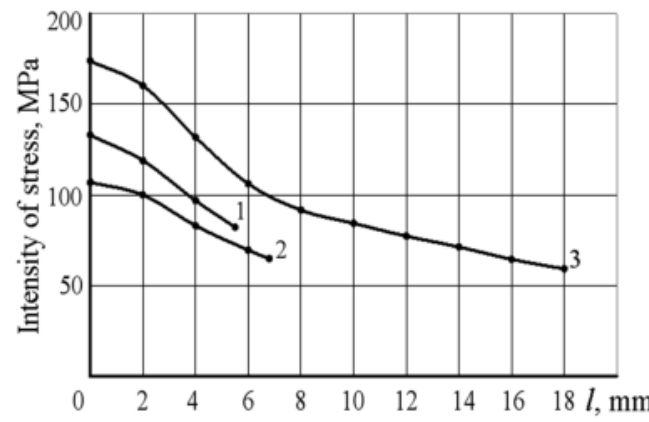

(a)

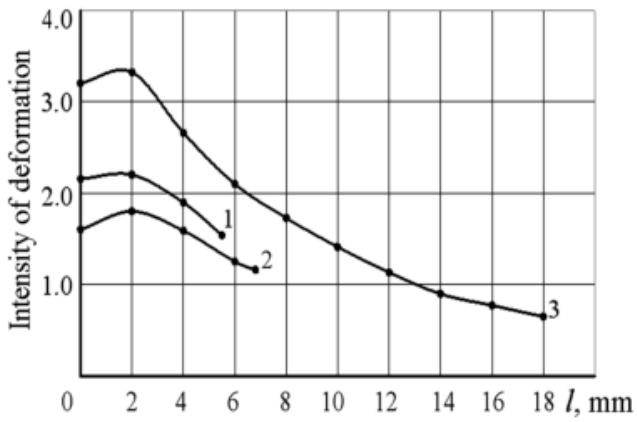

(b)

Figure 9. The distribution of the intensity of stress and intensity of deformation during extrusion of billet with relieving cavity $\left(a=15^{\circ}\right)$ : 1 - is the section $O A ; 2$ - is the section $O B ; 3$ - is the section $O C$. 
Thus, implementation of compacts with the relieving cavity and $\alpha=15^{\circ}$ was not ensured decreasing of non-uniformity of stress-strain state to an appropriate level. Consequently, in the transition region of spherical cavity in the hole during the final extrusion step a flaw is formed, but was not developed into a fold as the result of decreasing the non-uniformity of stress-strain state.

Increasing the angle $\alpha$ up to $30^{\circ}$ reduces non-uniformity of stress-strain state on $30 \%$. The largest and smallest $\sigma_{\mathrm{i}}$ and $\mathrm{e}_{\mathrm{i}}$ differ by 1.7 times and 2.1 times, respectively (Fig. 10). Parameters of stress-strain state are distributed more uniformly by sections. Consequently, a flow-through flaw was not formed in forged pieces during extrusion.

The results of analysis of non-uniformity of stress-strain state by sections of forged piece during extrusion of billets with relieving cavity at $\alpha=15^{\circ}$ and $\alpha=30^{\circ}$ are presented in Table 2.

\begin{tabular}{ccccc}
\hline \multirow{2}{*}{ Section of billet } & \multicolumn{2}{c}{$\boldsymbol{\sigma}_{\text {inh }}$} & \multicolumn{2}{c}{$\mathbf{e}_{\text {inh }}$} \\
\cline { 2 - 5 } & $\mathbf{a}=\mathbf{1 5}^{\circ}$ & $\mathbf{a}=\mathbf{3 0}^{\circ}$ & $\mathbf{a}=\mathbf{1 5}^{\circ}$ & $\mathbf{a = 3 0 ^ { \circ }}$ \\
\hline OA & 0.25 & 0.15 & 0.13 & 0.17 \\
\hline OB & 0.28 & 0.10 & 0.14 & 0.12 \\
\hline OC & 0.33 & 0.13 & 0.23 & 0.15 \\
\hline
\end{tabular}

Table 2. Evaluation of non-uniformity of stress-strain state at various values of the inclination angle of relieving cavity generatrix

The non-uniformity of stress-strain state in the sections OB and OC decreases with increasing of inclination angle of the relieving cavity generatrix that improving quality of forged piece, but does not completely eliminates defects. Further reduction of non-uniformity of stress-strain state by increasing the angle $\alpha$ was confirmed by simulation of radial direct extrusion of billets with spherical cavity at inclination angle $\alpha=5-45^{\circ}$ and radius of sphere $\mathrm{R}=6-16 \mathrm{~mm}$.

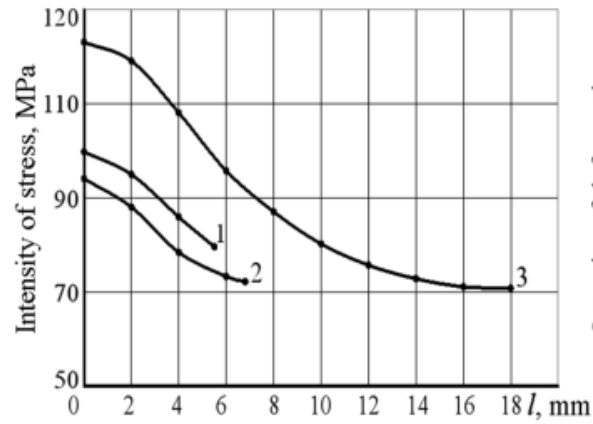

(a)

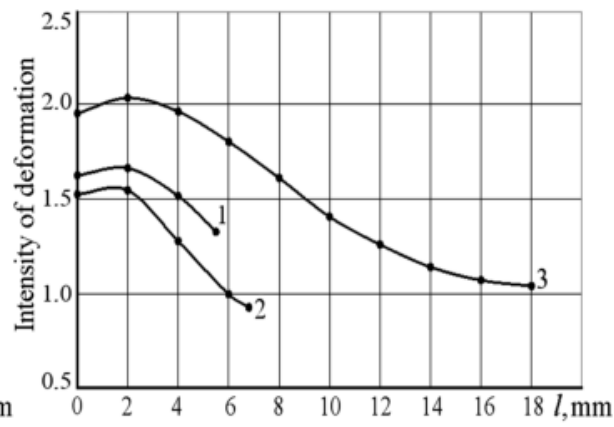

(b)

Figure 10. The distribution of the intensity of stress - (a) and deformation - (b) during extrusion of billets with relieving cavity $\left(a=30^{\circ}\right): 1$ - is the section OA; 2 - is the section OB; 3 - is the section OC. 
Dependences of the intensity of stress by layers of powder material for various radii of spherical cavity $\mathrm{R}$ and different values of angle $\alpha$ are presented on Fig. 11 according to the modelling results.

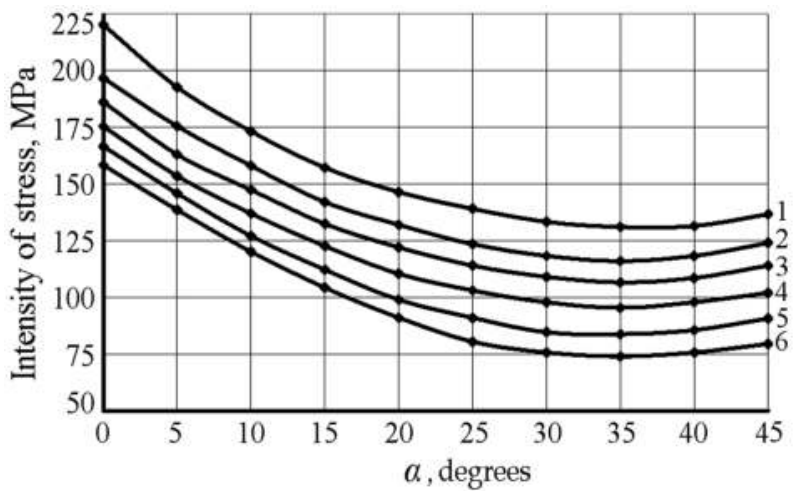

Figure 11. Dependences of maximum intensity of stress from the angle $a$ and radius $R: 1-R=16 \mathrm{~mm} ; 2-R=14 \mathrm{~mm} ; 3$ $-\mathrm{R}=12 \mathrm{~mm} ; 4-\mathrm{R}=10 \mathrm{~mm} ; 5-\mathrm{R}=8 \mathrm{~mm} ; 6-\mathrm{R}=6 \mathrm{~mm}$.

Analysis of dependences has shown that intensity of stress reaches a minimum at $\alpha=30$ $40^{\circ}$. The angle $\alpha$ is close to $40^{\circ}$ at increasing of $\mathrm{R}$, and angle $\alpha$ is close to $30^{\circ}$ while decreasing of $\mathrm{R}$. This means that the range of permissible values of angle $\alpha$ is within $30-40^{\circ}$.

Thus, to obtain the most uniform stress-strain state during radial-direct extrusion of forged pieces at $\mathrm{D}_{\text {flange }} / \mathrm{D}_{\text {out }}=1.1$, the billet with relieving cavity (Fig. 4 , b) and $\alpha=30-40^{\circ}$ may be recommended.

To verify the validity of this conclusion the distribution of stress-strain state parameters at $\alpha$ $=40^{\circ}$ in three sections of forged piece are presented on Fig. 12. Retrieved reduction of nonuniformity of stress-strain state by $6-10 \%$ at extrusion, according to (9), has compared with extrusion at $\alpha=30^{\circ}$.

The maximal values of the intensity of deformations are lower and shifted to deeper layers of forged piece at $2.3-4.0 \mathrm{~mm}$. The results of the non-uniformity analysis of stress-strain state by sections of forged piece with relieving cavity angle $\alpha=40^{\circ}$ are presented in Table 3. The non-uniformity of stress-strain states is lower for all three sections, in compare with extrusion at $\alpha=30^{\circ}$.

Therefore, extrusion of porous powder billets with relieving cavity having a generatrix inclination angle within $30-40^{\circ}$ provides a uniform stress-strain state.

Improvement of the uniformity of stress-strain state by using billets with relieving cavity allows obtaining a more uniform temperature field by the section of forged piece (Fig. 13).

Thus, the comparative analysis of the radial-direct extrusion of cylindrical billets with generatrix inclination angle $\alpha$ within $30-40^{\circ}$ has shown that the presence of relieving cavity 


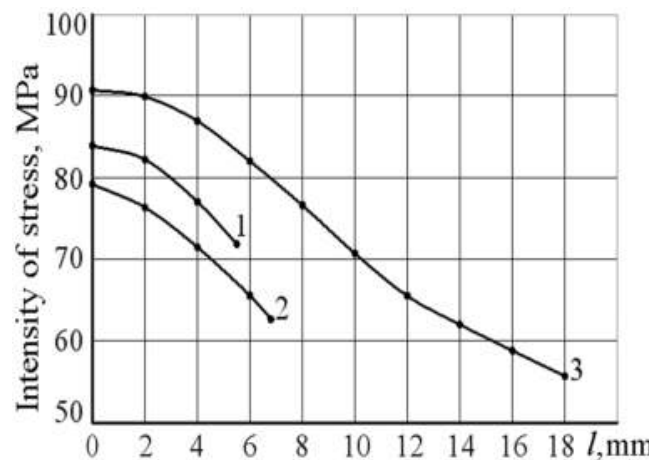

(a)

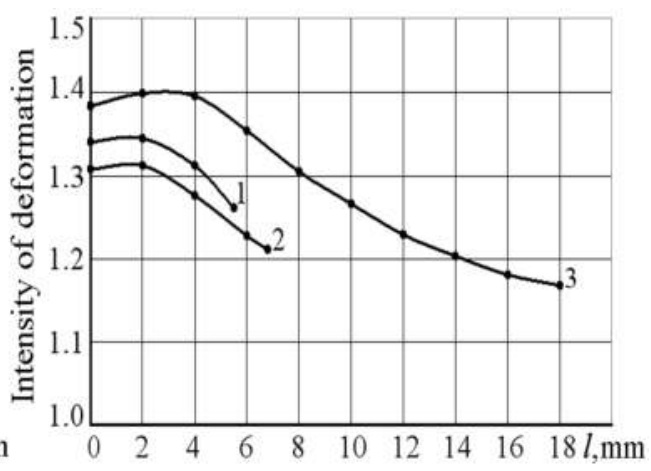

(b)

Figure 12. The distribution of the intensity of stress and intensity of deformation at extrusion of billets with relieving cavity $\left(a=40^{\circ}\right): 1$ - is the section OA; 2 - is the section OB; 3 - is the section OC.

increases the uniformity of the temperature field and stress-strain state. This helps to reduce the stress intensity and stress concentration factor $k_{\sigma}$ at the edges of the cavity by 3 - 4 times.

\begin{tabular}{ccc}
\hline Section of billet & $\boldsymbol{\sigma}_{\text {inh }}$ & $\mathbf{e}_{\text {inh }}$ \\
\hline OA & 0.08 & 0.01 \\
\hline OB & 0.06 & 0.01 \\
\hline OC & 0.08 & 0.03 \\
\hline
\end{tabular}

Table 3. Evaluation of non-uniformity of stress-strain state at the generatrix inclination angle $a=40^{\circ}$

As a result, the probability of flow-through flaw formation and risk of crack propagation during extrusion have diminished rapidly.

Analysis of the density changing by the volume of forged piece was simulated for extrusion of billet with the initial porosity $15 \%$, outer diameter $D_{\text {out }}=27 \mathrm{~mm}$ and diameter of hole $9 \mathrm{~mm}$. The density variation and equidensity at different conditions of radial direct extrusion of forged piece have been investigated.

The most difficult is to ensure equidensity at extrusion of flange of forged piece due to tensile stresses. Therefore, density distribution is presented by section OA (Fig. 14) where the highest probability of defects formation occurs.

The maximum density of $7.77 \mathrm{~g} / \mathrm{cm}^{3}$ during extrusion of billets without relieving cavity at ratio $\mathrm{D}_{\text {flange }} / \mathrm{D}_{\text {out }} 1.1$ - 1.3 (Fig. 14, a) was reached in the volume of metal adjacent to the surface of forged piece at $\mathrm{D}_{\text {flange }} / \mathrm{D}_{\text {out }}=1.1$ that does not corresponding to the density of compact material. This is due to the increase of tensile stress, leading to a tightening of the surface layer of the metal forging deeper. Moreover, the greater a flange, the more decrease in density of metal 

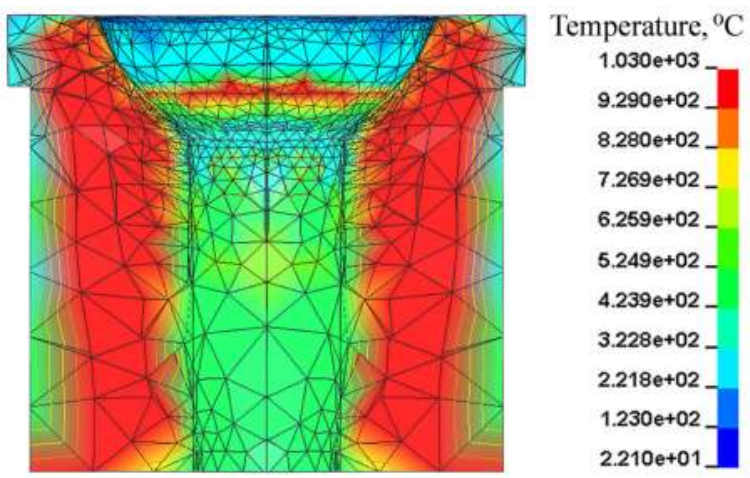

Figure 13. The temperature field of the billet at extrusion of billet with relieving cavity at $a=40^{\circ}$.

adjacent to the surface of sphere and in the flange. A density close to $7.83 \mathrm{~g} / \mathrm{cm}^{3}$ has obtained in the billet at $\alpha=15^{\circ}$ only at the ratio $\mathrm{D}_{\text {flange }} / \mathrm{D}_{\text {out }}=1.1$ (Fig. $14, \mathrm{~b}$ ).

In two other cases, it decreases by the volume of flange, but with a smaller gradient. A high density obtained for $\mathrm{D}_{\text {flange }} / \mathrm{D}_{\text {out }}=1.1-1.2$ at different initial density while increasing angle $\alpha$ to $30^{\circ}$ (Fig. 14, c). However, if $\mathrm{D}_{\text {flange }} / \mathrm{D}_{\text {out }}=1.3$ the density of compact material obtained. The high density has obtained at the cavity angle $\alpha=40^{\circ}$ for $\mathrm{D}_{\text {flange }} / \mathrm{D}_{\text {out }}=1.1-1.2$ (Fig. 13, d). It is rather difficult to change the volume of forged piece at any density for $D_{\text {flange }} / D_{\text {out }}=1.3$. Pores and cracks were appeared on spherical surface of the metal due to increased loosening at radial flow of metal in the gap and on the side of flange.

Simulation of the density distribution at $\mathrm{D}_{\text {flange }} / \mathrm{D}_{\text {out }}=1.3$ during extrusion of billets with $10 \%$ initial porosity and inclination angle of relieving cavity generatrix $40^{\circ}$ shown the density variation within $7.79-7.81 \mathrm{~g} / \mathrm{cm}^{3}$ that indicates a possibility to obtain the equidence and highstrength details.

\section{Determination of extrusion force}

One of the most important problems during development of metal forming technologies for powder billets is determination of deforming force that is necessary for reasonable choice of pressing equipment. The analytical expression of extrusion force $\mathrm{P}$ in polar coordinates for known average intensity of stress $\sigma_{i}^{\text {ave }}$ on the contact surface of upper punch and powder billet or function for $\sigma_{i}$ may be written in the following way (Wagoner \& Chenot, 2001):

$$
P=\iint_{F} \sigma_{i} r d r d \phi=\int_{0}^{r} d r \int_{0}^{2 \pi} \sigma_{i} r d \phi,
$$

where $\mathrm{F}$ - is the area of contact surface of upper punch and powder billet. 


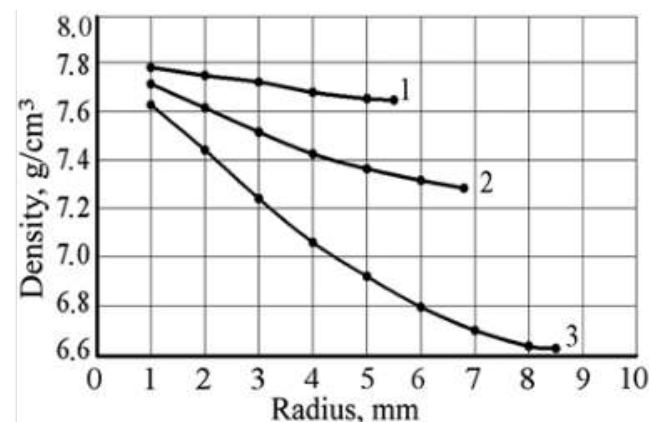

(a)

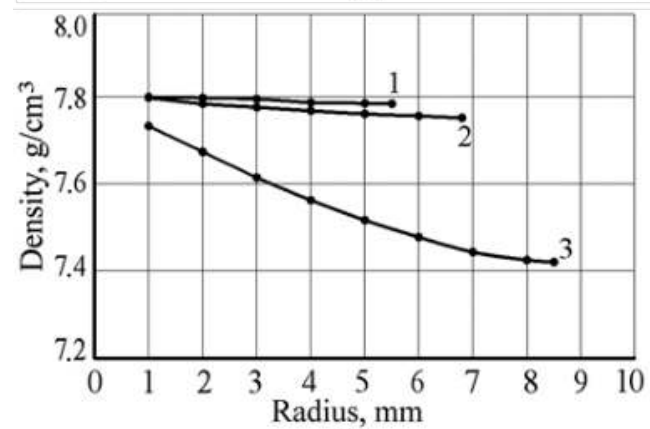

(c)

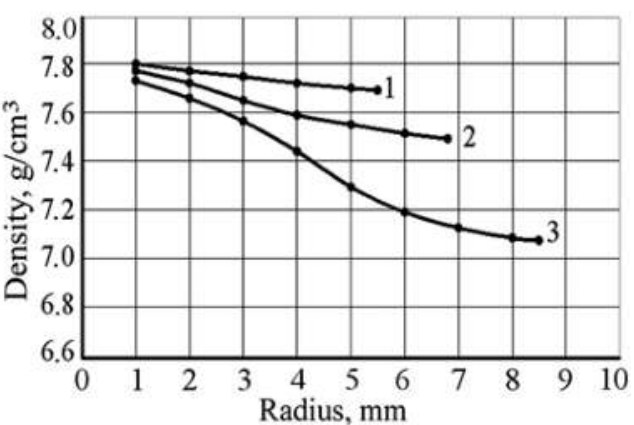

(b)

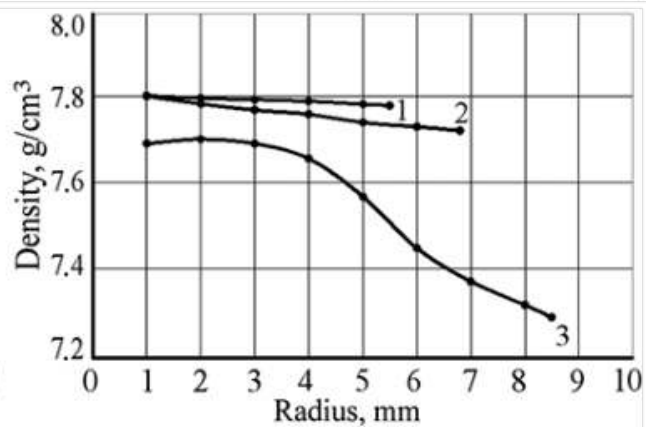

(d)

Figure 14. Density distribution by the section OA of forged piece (a) - with no relieving cavity; (b, $c, d)$ - with the relieving cavity (generatrix inclination angle $a$ is $15,30,40^{\circ}$, respectively): $1-D_{\text {flange }} / D_{\text {out }}=1.1 ; 2-D_{\text {flange }} / D_{\text {out }}=1.2 ; 3-$ $D_{\text {flange }} / D_{\text {out }}=1.3$.

The expression (13) for radial-direct extrusion of forged piece with spherical cavity and central hole with accounting the modelling results may be transformed to:

$$
P=\int_{D_{\text {hole }}}^{D_{\text {flange }}} \frac{1}{2} d D \int_{0}^{2 \pi} \sigma_{i} D d \varphi=\frac{\sigma_{i}^{\text {ave }} \pi\left(D_{\text {flange }}^{2}-D_{\text {hole }}^{2}\right)}{4},
$$

where $D_{\text {flange }}$ - is the outer diameter of flange;

$\mathrm{D}_{\text {hole }}$ - is the diameter of hole.

Values of extrusion force calculated by formula (14) at different inclination angles of generatrix of relieving cavity for $D_{\text {flange }} / D_{\text {out }}=1.1$ and height of the cavity $6 \mathrm{~mm}$ are presented in the Table 4 .

The dependence of extrusion force from the relative flange size is presented in the Table 5 ( $\alpha$ $=40^{\circ}$, diameter of sphere $\mathrm{D}_{\mathrm{sf}}=20 \mathrm{~mm}$ ). 


\begin{tabular}{ccc}
\hline$a^{\circ}$ & $\sigma_{i}^{a v e}, \mathrm{MPa}$ & $\mathrm{P}, \mathrm{kN}$ \\
\hline 0 & 133.1 & 92.0 \\
\hline 15 & 118.2 & 81.7 \\
\hline 30 & 103.7 & 71.6 \\
\hline 40 & 84.5 & 58.4 \\
\hline
\end{tabular}

Table 4. Extrusion force at different inclination angles of generatrix of relieving cavity for $D_{\text {flange }} / D_{\text {out }}=1.1$

\begin{tabular}{ccc}
\hline$D_{\text {flange }} / \mathrm{D}_{\text {out }}$ & $\sigma_{i}^{\text {ave }}, \mathrm{MPa}$ & $\mathrm{P}, \mathrm{kN}$ \\
\hline 1.1 & 84.5 & 58.4 \\
\hline 1.2 & 106.2 & 89.6 \\
\hline 1.3 & 127.4 & 124.5 \\
\hline
\end{tabular}

Table 5. The extrusion force at different flange size, $\alpha=40^{\circ}\left(D_{\mathrm{sf}}=20 \mathrm{~mm}\right)$

The results of computer modelling and laboratory experiments are well concordant with relative error $7-9 \%$.

\section{Conclusions}

In this chapter the results of computer modelling of radial direct extrusion of forged piece with the spherical cavity and small flange from a cylindrical billet with a porosity of $15 \%$ and axial hole have shown a high non-uniformity of the stress-strain state, temperature field and density distribution by sections of forged piece that leads to appearing of defects are reported. It has been shown, among other, how the smallest non-uniformity of the stress-strain state, temperature field and maximum density indicate a possibility to obtain high-quality products.

A high-quality details with a spherical cavity and the ratio $D_{\text {flange }} / D_{\text {out }}=1.2$ may be obtained from powder billets with $15 \%$ initial porosity and relieving cavity with generatrix inclination angle $40^{\circ}$. Details with the ratio $D_{\text {flange }} / D_{\text {out }}=1.3$ may not be produced from such billets due to the presence of cracks and non-uniformity into the flange. High-quality details with the ratio $D_{\text {flange }} / D_{\text {out }}=1.3$ may be made from billets of $10 \%$ initial porosity and relieving cavity with generatrix inclination angle within $30-40^{\circ}$.

The highest density of $7.80-7.83 \mathrm{~g} / \mathrm{cm}^{3}$ and the equidensity of flange observed in forged pieces at the ratio $D_{\text {flange }} / D_{\text {out }}=1.1-1.2$, obtained from billets with generatrix inclination angle of relieving cavity within $30-40^{\circ}$ and initial porosity of $15 \%$. Forged pieces with $D_{\text {flange }} / D_{\text {out }}=1.3$ and density $7.79-7.81 \mathrm{~g} / \mathrm{cm}^{3}$ may be produced from powder billets with generatrix inclination angle of relieving cavity within $30-40^{\circ}$ and $10 \%$ initial porosity.

The simulation and experimental results are well concordant with relative error 7 - $9 \%$. 


\section{Author details}

Lyudmila Ryabicheva* and Dmytro Usatyuk

Volodymyr Dahl East Ukrainian National University, Ukraine

\section{References}

[1] Awrejcewicz, J., Andrianov, I.V., Manevitch, L.I. (2004). Asymptotical Mechanics of Thin-Walled Structures. A Handbook. Springer-Verlag, Berlin.

[2] Awrejcewicz, J., Krysko, V.A., Krysko, A.V. (2007). Thermodynamics of Plates and Shells. Springer-Verlag, Berlin.

[3] Awrejcewicz, J., Pyryev, Yu. (2009). Nonsmooth Dynamics of Contacting Thermoelastic Bodies. Springer-Verlag, New York.

[4] Aliev, I.S., Solodun, E.M., Nosakov, A.A., and Kruger, K. (2001). Modeling of Combined Extrusion Processes, Nowe Technologie i Osiqgniecia w Metalurgie i Inzynierii Materialowej, II Miedzynarodowa Sesja Naukowa, Wydawnictwo Wydzialu Metalurgii i Inzynierii Materialowej Politechniki Czestochowskiej. - P. 195-200.

[5] Favrot N., Besson, J., Colin, C., Delannay, F., and Bienvenu, Y. (1997). Modeling Sintering Deformations Occurring After Cold Compaction, Qualitative Methods for the Mechanics of Compaction, Proceedings of the International Workshop on Modeling of Metal Powder Forming Process, Grenoble, 21-23 July. - P. 133-147.

[6] Lienhard, IV, J.H., Lienhard, V, J.H. (2003). A Heat Transfer Textbook, Phlogiston Press. Cambridge, Massachusetts.

[7] Ryabicheva, L.A., Tsirkin, A.T., Nikitin, Yu.N., Beloshitskij, N.V., and Lubchich, K.V. (2011). Technologies for Production of Complex-shaped Details From Powder Materials, Resursozberìgaûči Tehnologiï Virobnictva ta Obrobki Tiskom Materìalìv u Mašino-buduvannì, Volodymyr Dahl East Ukrainian National University, Lugansk. - P. 189198.

[8] Ryabicheva, L., Usatyuk, D., Lyubchich, K. (2011) Radial-direct extrusion of details with spherical cavity from powder porous billets with relieving cavity, 8th International Congress "Machines, Technologies, Materials 2011", September 18-20, 2011, Varna, Bulgaria, V. 1. - P. 116-119.

[9] Ryabicheva, L., Orlova, Y. Analysis of densification of porous powder billets on a basis of extended model of plastic flow, Lugansk, Volodymyr Dahl East Ukrainian National University. No. 1(13), (2012). - P. 227-234. 
[10] Ryabicheva L., Usatyuk, D., Beloshitskij, N. Computer modelling of radial-direct extrusion of complex-shaped details. Journal of Computer and Information Technology, Vol. 2, No. 1 (2012). - P. 91-101.

[11] Ryabicheva, L. Modeling of direct extrusion of porous powder billets. Advanced Materials Research, Vol. 566, (2012). - P. 267-270.

[12] Ryabicheva, L., Usatyuk, D., Ryabovol, T. (2012). Production of high-density copper-titanium powder material by angular extrusion with back pressure, XIII International Scientific Conference New Technologies and Achievements in Metallurgy and Material Engineering, 30 May - 1 June, 2012, Ch. 2, Czestochowa, Poland. - P. 698-701.

[13] Ryabicheva, L.(2012). Development of the theory and production technology of machinebuilding parts from powder materials, MTM'12 Conference proceedings, 18-21 September, 2012, Varna, Bulgaria.

[14] Segal, V.M., Reznikov, V.I., Kopilov, V.I., Belarus (1994). The Plastic Structure Formation Processes in Metals, Minsk, Nauka i Technika.

[15] Segal, V.M., Reznikov, V.I. \& Malyshev, V.F. Variational functional for a porous plastic body, Powder Metallurgy and Metal Ceramics, Vol. 20, No. 9 (1981). - P. 604-607.

[16] Shtern, M.B., Serdyuk, G.G., and Maximenko, L.A. (1982). Phenomenological Theories of Pressing of Powders, Naukova Dumka.

[17] Skorokhod, V.V., Ukraine (1973). The Rheological Basics of Sintering Theory, Naukova Dumka.

[18] Shtern, M.B., Development of the theory of pressing and plastic deformation of powder materials, Powder Metallurgy and Metal Ceramics, No. 9 (1992). - P. 735-745.

[19] Shtern, M.B. Determining equations for compressible plastic porous solids, Powder Metallurgy and Metal Ceramics, No. 4 (1981). - P. 250-255.

[20] Skorokhod, V.V. (1985). The topical problems of continuum theory of structural modelling of deforming processes of powders and porous bodies, rheological models and processes of deforming of porous powder and composite materials, Naukova Dumka, Kiev. - P. 6-11.

[21] Stoker, H.C., Netherlands (1999). Developments of the Arbitrary Lagrangian-Eulerian Method in Non-linear Solid Mechanics, Applications to Forming Processes, Ph.D - Thesis, University of Twente, P. 23-82.

[22] Wagoner, R. H. \& Chenot, J. L. (2001). Metal Forming Analysi s, Cambridge University Press, ISBN 0-521-64267-1, Cambridge.

[23] Wisselink, H.H., Netherlands (2000). Analysis of Guillotining and Slitting, Finite Element Simulations, Ph.D-Thesis, University of Twente. - P. 33-66. 
